\title{
Rancang Bangun Alat Pengering Pelepah Pisang (Menggunakan Metode Controller Chien Regulator I dan Chien Servo I Sebagai Tuning Kontrol PI)
}

\author{
Irianto $^{[[1]}$, Suhariningsih ${ }^{2]}$, Viviana Ratna \\ Dewanti $^{[3]}$ \\ Program Studi D3 Teknik Elektro Industri \\ Departemen Teknik Elektro
}

\begin{abstract}
Abstrak - . Pisang memberi banyak manfaat untuk kesehatan karena mempunyai kandungan vitamin A yang cukup untuk kebutuhan vitamin tubuh sehari-hari. Manfaat pisang tidak hanya terdapat pada buahnya saja. Pelepah pisang jarang dimanfaatkan keberadaannya karena dinilai tidak memiliki manfaat lebih dan hanya dianggap sebagai limbah. Namun, pelepah pisang bisa diubah menjadi berbagai bentuk kerajinan yang cantik dan bernilai ekonomi tinggi. Pelepah pisang dikeringkan terlebih dahulu sebelum diproses menjadi berbagai kerajinan tangan. Proses pengeringan pelepah pisang ini sangat bergantung pada kondisi cuaca dan teriknya sinar matahari. Proses pengeringan pelepah pisang secara konvensional memakan waktu kurang lebih 70 jam dengan suhu matahari sekitar $40^{\circ} \mathrm{C}$. Solusi untuk permasalahan ini adalah, merancang dan membuat alat pengering pelepah pisang berbasis mikrokontroller menggunakan kontrol PI untuk mengatur suhu dan memanfaatkan heater sebagai sumber panas alternatif. Kontrol PI ini menggunakan metode tuning Chien Regulator I dan Chien Servo I. Pada Proyek Akhir ini dilakukan pengaturan temperatur dan pengukuran kadar air pelepah pisang. Kontrol akan mengatur exhaust fan bila suhu terbaca oleh LM35 yang ditampilkan pada LCD 4x20 untuk monitoring suhu. Untuk mengatur tegangan keluaran $A C-A C$ voltage controller pada heater, bergantung pada sudut penyulutan dari IC TCA785. DAC dari Mikrokontroller ATMega16 akan mengkonversi data digital yang dikeluarkan mikrokontroller menjadi tegangan analog. Nilai Kp dan $\mathrm{Ki}$ yang digunakan yaitu $K p=5$ dan $\mathrm{Ki} 0.625$ menggunakan metode Chien Regulator I serta nilai $K p=4.126$ dan Ki 0.414 menggunakan metode Chien Servo I Proses pengeringan memerlukan waktu lebih cepat yaitu 16 jam dengan kadar air sebesar $4.76 \%$ pada suhu $\pm 65^{\circ} \mathrm{C}$ menggunakan metode Chien Servo I karena respon suhu lebih stabil.
\end{abstract}

Kata kunci:Pelepah pisang, $A C$ to $A C$ Voltage Controller, IC TCA 785, LM35, Mikrokontroller ATMega16, Chien Regulator I, Chien Servo I

Abstract - . Bananas provide many health benefits because they have enough vitamin A for daily body vitamins. Benefits of bananas are not only found in the fruit alone. Banana stem is rarely used because it is

\author{
Politeknik Elektronika Negeri Surabaya \\ Kampus PENS, Jalan Raya ITS Sukolilo, \\ Surabaya 60111 \\ Email: \\ dewanti100@gmail.com ${ }^{[1]}$, irianto@pens.ac.id ${ }^{[2]}$, \\ nuning@pens.ac.id
}

considered not to have more benefits and is only considered as waste. However, banana stem can be transformed into various forms of beautiful crafts and high economic value. Banana banana is dried first before being processed into various handicrafts. The process of drying banana is very dependent on the weather conditions and the heat of the sun. Conventional banana drying process takes approximately 70 hours with a solar temperature of about $40 o C$. The solution to this problem is, design and manufacture a microcontroller based banana bum dryer using PI control to regulate the temperature and utilize the heater as an alternative heat source. This PI control uses Chien Regulator I and Chien Servo I tuning methods. In this Final Project, temperature and banana moisture content is measured. The control will adjust the exhaust fan when the temperature read by LM35 is displayed on LCD $4 \times 20$ for temperature monitoring. To adjust the $A C-A C$ voltage controller voltage on the heater, depending on the angle of ignition of the TCA785 IC. DAC of Microcontroller ATMega16 will convert the digital data released microcontroller into analog voltage. The $K p$ and $K i$ values used are $K p=5$ and Ki 0.625 using Chien Regulator I method and $\mathrm{Kp}=4,126$ and Ki 0.414 using Chien Servo I method The drying process takes 16 hours with water content of $4.76 \%$ at \pm 65oC using Chien Servo I method because the temperature response is more stable.

Keywords: Banana stem, AC to AC Voltage Controller, IC TCA 785, LM35, Microcontroller ATMega16, Chien $\begin{array}{lllll}\text { Regulator } I, & \text { Chien }\end{array}$ 


\section{PENDAHULUAN}

Pelepah pisang jarang dimanfaatkan keberadaannya karena dinilai tidak memiliki manfaat lebih dan hanya dianggap sebagai limbah. Namun, pelepah pisang bisa diubah menjadi berbagai bentuk kerajinan dan furnitur yang bernilai ekonomi tinggi. Kerajinan dan furnitur dari pelepah pisang merupakan bahan organik yang ramah lingkungan sehingga penggunaannya sangat bermanfaat untuk mengurangi dampak pemanasan global. Pelepah pisang dikeringkan terlebih dahulu sebelum diproses menjadi berbagai kerajinan tangan dan furnitur.

Untuk dapat dipasarkan pelepah pisang harus melalui beberapa proses pengolahan, salah satunya adalah mengeringkan pelepah pisang di terik matahari agar kadar air pada pelepah pisang berkurang. Dan permasalahan yang timbul pada proses pengeringan pelepah pisang yaitu :

- Waktu pengeringan memakan banyak waktu.

- Tidak dapat melakukan proses pengeringan di malam hari.

Proses pengeringan kurang maksimal dalam cuaca yang mendung. Dari masalah-masalah tersebut maka tujuan proyek akhir ini adalah perancangan sebuat alat yang dapat melakukan proses pengeringan secara otomatis dan lebih cepat dari menggunakan terik matahari. Alat yang akan dirancang ini menggunakan mikrokontroller sebagai pusat kontrol dan sensor LM35 untuk membaca suhu pada ruang pengering. Dengan adanya alat ini diharapkan dapat menyelesaikan permasalahan-permasalahan yang ada pada usaha kerajinan dari pelepah pisang. Oleh karena itu pada proyek akhir ini akan di buat alat pengering yang otomatis. Untuk menyempurnakan tujuan diatas maka digunakan beberapa referensi yaitu :

- Mochamad Shobirin yang berjudul "Rancang Bangun Alat Pengering Helm Berbasis Mikrokontroller" dari referensi ini dimengerti blok diagram dan cara kerja mulai dari sumber ac, pengontrolan heater dengan mikrokontroller hingga cara kerja sensor suhu LM35.

- Sofyan Muhammad Ilman yang berjudul "Rancang Bangun Pengaturan Suhu Air Dispenser dengan Kontrol PI" dari judul ini

- dimengerti pengontrollan suhu menggunakan metode tuning Chien Regulator I dan Chien Servo I.

Dari kedua referensi diatas maka dalam proyek akhir ini akan di buat perancangan alat penggabungan kedua penelitian diatas yaitu pengontrolan heater terhadap perubahan suhu menggunakan mikrokontroler untuk pengeringan daun tembakau rajangan dengan masukan dari sensor suhu LM35.

\section{METODE}

Perancangan dan pembutan proyek akhir ini berpatokan pada blok diagram sistem serta alur kerja dari blok diagram. Berikut merupakan gambaran umum sistem pengeringan pelepah pisang yang ditunjukkan seperti pada gambar 1 .

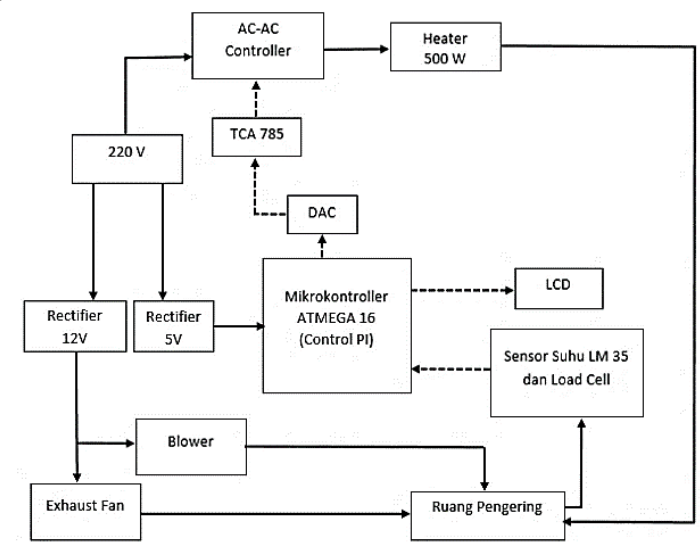

Gambar 1. Blok Diagram Sistem

Gambar 1 diatas adalah blok diagram sederhana untuk menjelaskan alur kontrolnya untuk alur pekerjaan otomatisnya akan dijelaskan seperti berikut. Proses kerja dari alat pengering pelepah pisang yaitu dengan proses pengaturan suhu panas pada ruang pengering dalam kondisi yang tetap sebesar $65^{\circ}$ celcius menggunakan metode kontrol PI ( Proportional Integral ). Dengan menggunakan perangkat Ac - Ac Voltage Controlled, TCA785 dan DAC sebagai pengontrol tegangan keluaran pada heater guna pengoptimalan suhu pada ruang pengering. Sensor suhu LM35 yang terpasang pada ruang pengering berfungsi sebagai umpan balik pada sistem kontrol suhu agar tetap sesuai dengan set point yang telah ditentukan. Blower fan digunakain untuk meratakan panas heater pada ruang pengering, sedangkan Exhaust fan berfungsi untuk mengeluarkan uap air dari hasil pengeringan. Sistem akan berhenti apabila proses telah berjalan sesuai dengan waktu yang ditentukan pada sistem.

\subsection{Mikrokontroler ATMegal6}

Mikrokontroler adalah salah satu dari bagian dasar dari suatu sistem komputer. Seperti pada umumnya komputer, mikrokontroler adalah alat yang mengerjakan instruksi-instruksi yang diberikan. Artinya, bagian terpenting dan utama dari suatu sistem terkomputerisasi adalah program itu sendiri yang dibuat oleh seorang programmer. Program ini menginstruksikan komputer untuk melakukan jalinan yang panjang dari aksi-aksi sederhana untuk melakukan tugas yang lebih komplek.

Keuntungan menggunakan mikrokontroler adalah harganya murah, dapat diprogram berulang kali, dan dapat diprogram sesuai dengan keinginan kita.

Mikrokontroler ATMega16 memiliki fitur yang lengkap (ADC internal, EEPROM internal, Timer/Counter, Watchdog Timer, PWM, Port I/O, komunikasi serial, Komparator, I2C,dll.).

Berikut ini merupakan beberapa spesifikasi ATMega16:

- Arsitektur RISC dengan throughput mencapai 16 MIPS pada frekuensi $16 \mathrm{Mhz}$.

- Memiliki kapasitas flash memori 16Kbyte, EEPROM 512 Byte, dan SRAM 1Kbyte

- Saluran Port I/O sebanyak 32 buah, yaitu Port A, Port B, Port C, dan Port D. 
- CPU yang terdiri atas 32 buah register

- User interupsi internal dan eksternal

- Port USART sebagai komunikasi serial

- Konsumsi daya rendah (DC 5V)

- Fitur peripheral, yang terdiri dari:

a. Tiga buah Timer/Counter dengan perbandingan 2 (dua) buah Timer/Counter 8 bit dengan Prescaler terpisah dan Mode Compare, 1 (satu) buah Timer/Counter 16 bit dengan Prescaler terpisah, Mode Compare, dan Mode Capture.

b. Real Time Counter dengan osilator tersendiri.

c. 4 channel PWM

d. 8 channel, 10-bit ADC

- 8 Single-ended Channel

- 7 Differential Channel hanya pada kemasan TQFP

- 2 Differential Channel dengan Programmable Gain 1x, 10x, atau 200x

e. Byte-oriented Two-wire Serial Interface.

f. Antamuka SPI.

g. Watchdog Timer dengan osilator internal.

h. On-chip Analog Comparator

\subsection{Ac to Ac Voltage Controlled}

Untuk dapat merubah tegangan $\mathrm{AC}$ yang yang bernilai tetapmenjadi tegangan AC yang memiliki besaran yang dapat diatur salahsatunya adalah dengan metode kontrol fasa. Metode kontrol fasa akanbekerja dengan meredam bagian dari gelombang sinusoidal setiap setengah periode atau satu periode penuh. Komponen yang dapat digunakan untuk metode ini adalah TRIAC atau sepasang thyristor yang dipasang secara berlawanan arah. Gambar 2.2 merupakan gambar kontrol fasa menggunakan TRIAC.

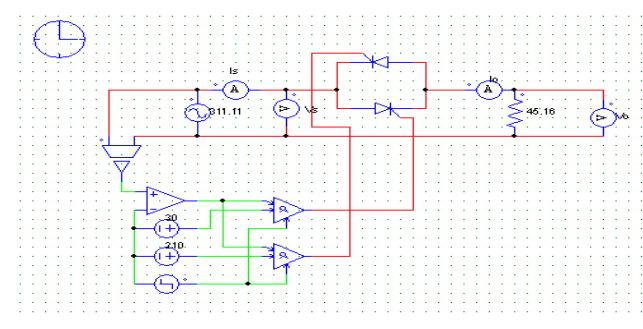

\section{Gambar 2. Rangkaian Ac to Ac Voltage Controlled.}

Rangkaian kontrol fasa biasanya digunakan sebagai kontrol heater dan kontrol kecepatan motor universal. Pada rangkaian kontrol fasa frekuensi keluaran dari rangkaian sama seperti frekuensi sumbernya. Kondisi TRIAC terbuka atau tertutup tergantung pada penyulutan dari gate driver. TRIAC akan pada kondisi terbuka jika gate pada TRIAC tidak mendapatkan penyulutan, pada kondisi ini terdapat bagian dari gelombang sinus yang teredam sepanjang beberapa derajat. Jika gate pada komponen TRIAC mendapatkan penyulutan, maka TRIAC pada kondisi tertutup sesuai besarnya sudut penyulutan yang diberikan, sehingga pada kondisi ini gelombang sinus dapat muncul namun tidak secara penuh dan jika dilihat dari gelombang sinusoidalnya.

\subsection{Heater}

Filament heater adalah elemen pemanas berbentuk U yang biasanya digunakan untuk sistem pemanasan kering, udara, tepatnya blower, karena sirip-sirip yang mengelilinginya sangat efektif untuk memecah panas agar merata ke setiap bagian ruangan yang memerlukan pemanasan, Heater ini juga biasa digunakan untuk Load Bank heater, untuk mengoptimalkan penggunaan heater ini dengan bentuk yang dibutuhkan, biasanya dengan satu tekukan sampai lima tekukan. Setiap element heater memiliki daya yang berbeda-beda tergantung dari penggunaannya, untuk memanaskan ruang dengan lebih cepat dan dengan suhu yang lebih panas biasanya digunakan element heater dengan daya yang besar pula.

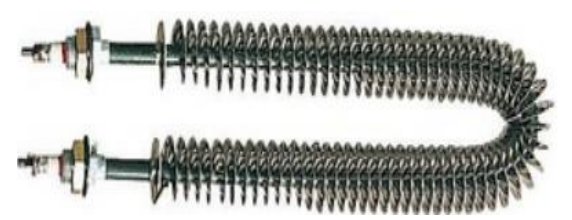

\section{Gambar 3. Bentuk Fisik Heater.}

Pada proyek akhir ini element heater yang digunakan untuk proses pengeringan daun tembakau adalah sebesar 450 Watt,bentuk ruang pengering di desain berbentuk tabung agar udara panas dapat di buat merata.

\subsection{Sensor Suhu dan Kelembaban (SHT11)}

Sensor suhu IC LM 35 berfungsi untuk mengetahui temperature suatu objek atau ruangan dalam bentuk besaran elektrik, atau dapat juga di definisikan sebagai komponen elektronika yang berfungsi untuk mengubah perubahan temperature yang diterima dalam perubahan besaran elektrik. Sensor suhu IC LM35 dapat mengubah perubahan temperature menjadi perubahan tegangan pada bagian outputnya. Sensor suhu IC LM35 membutuhkan sumber tegangan DC +5 volt dan konsumsi arus DC sebesar $60 \mu \mathrm{A}$ dalam beroperasi.

- Spesifikasi dari LM35 ini adalah sebagai berikut:

1. Memiliki sensitivitas suhu, dengan faktor skala linier antara tegangan dan suhu $10 \mathrm{mVolt} /{ }^{\circ} \mathrm{C}$, sehingga dapat dikalibrasi langsung dalam celcius.

2. Memiliki ketepatan atau akurasi kalibrasi yaitu $0,5^{\circ} \mathrm{C}$ pada suhu $25^{\circ} \mathrm{C}$.

3. Memiliki jangkauan maksimal operasi suhu antara $55^{\circ} \mathrm{C}$ sampai $+150{ }^{\circ} \mathrm{C}$. Bekerja pada tegangan 4 sampai 30 volt.

4. Memiliki arus rendah yaitu kurang dari $60 \mu \mathrm{A}$.

5. Memiliki pemanasan sendiri yang rendah (lowheating) yaitu kurang dari $0,1^{\circ} \mathrm{C}$ pada udara diam. 
6. Memiliki impedansi keluaran yang rendah yaitu 0,1 $\mathrm{W}$ untuk beban $1 \mathrm{~mA}$.

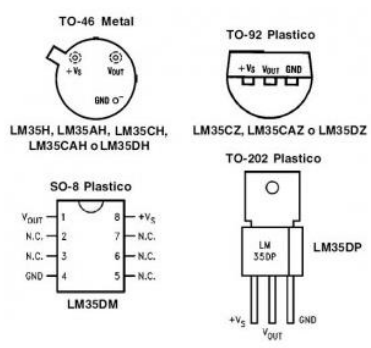

Gambar 4 Bentuk Fisik Sensor LM35.

Sensor suhu IC LM35 memiliki keakuratan tinggi dan mudah dalam perancangan jika dibandingkan dengan sensor suhu yang lain, sensor suhu LM35 juga mempunyai keluaran impedansi yang rendah dan linieritas yang tinggi sehingga dapat dengan mudah dihubungkan dengan rangkaian kontrol khusus serta tidak memerlukan seting tambahan karena output dari sensor suhu LM35 memiliki karakter yang linier dengan perubahan $10 \mathrm{mV} /{ }^{\circ} \mathrm{C}$. Sensor suhu LM35 memiliki jangkauan pengukuran $-55^{\circ} \mathrm{C}$ hingga $+150^{\circ} \mathrm{C}$ dengan akurasi $\pm 0.5^{\circ} \mathrm{C}$.

\subsection{Model Proses Self Regulating}

Model proses self regulating adalah model proses yang bersifat stabil. yang didekati oleh sebuah model matematis yang dikenal dengan

nama model FOPDT (First Order Plus Dead Time) yang dicirikan oleh tiga buah parameter yaitu keterlambatan transportasi (L), konstanta waktu proses (T) dan gain statis proses (K). Model self regulating proses hampir muncul pada setiap kasus pengontrolan praktis, seperti pengontrolan temperatur pada sistem heat exchanger, pengontrolan level fluida pada sistem tangki penampung, dan sebagainya. Seperti yang telah disebutkan bahwa model self regulating process pada dasarnya dapat didekati oleh sebuah model matematis FOPDT (First Order Plus Dead Time) yang hanya dicirikan oleh tiga buah parameter berikut :

- Process transport delay (delay keterlambatan transportasi proses) - $\mathrm{L}$

- Process time constant (konstanta waktu proses) - T

- Process static gain (gain statis proses) - K

Ketiga parameter yang menggunakan dinamika proses tersebut, secara praktis dapat diperoleh atau diidentifikasi melalui test sinyal tangga secara open loop pada mode kontrol manual.

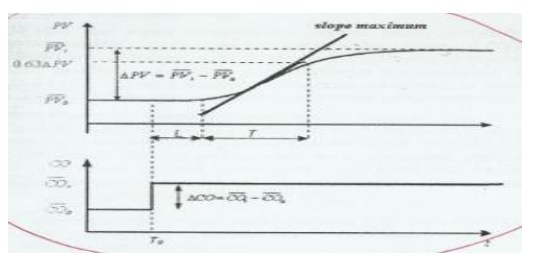

Gambar 5. Respon tangga untuk model FOPDT

\subsection{Metode Chien Regulator I dan Chien Servo I}

Metode Chien Servo 1 digunakan sebagai tuning kontrol PI pada model proses FOPDT (First Order Plus Dead Time). Metode Chien Servo 1 memiliki sepesifikasi sebagai berikut :
a. Tanpa overshoot

b. $0,11<\frac{L}{T}<1$

Persamaan yang digunakan pada metode Chien Servo 1 adalah sebagai berikut:

$\mathrm{Kp}=\frac{0,35 T}{K L}$

$\tau_{\mathrm{i}}=1,17 \mathrm{~T}$

Dengan keterangan sebagai berikut :

$\mathrm{L}=$ Keterlambatan transportasi proses

$\mathrm{K}=$ Gain statis proses

$\tau=\mathrm{T}=$ Tetapan waktu proses

Selain metode Chien Servo 1, proyek akhir ini menggunakan metode Chien Regulator 1 sebagai

tuning kontrol PI. Spesifikasi metode Chien Regulator 1 sama dengan spesifikasi dari metode Chien Servo 1 yaitu sebagai berikut :

a. Tanpa overshoot

b. $\quad 0,11<\frac{L}{T}<1$

Persamaan yang digunakan pada metode Chien Regulator 1 adalah sebagai berikut:

$\mathrm{Kp}=\frac{0,6 T}{K L}$

$\tau_{\mathrm{i}}=4 \mathrm{~L}$

Dengan keterangan sebagai berikut :

$\mathrm{L}=$ Keterlambatan transportasi proses

$\mathrm{K}=$ Gain statis proses

$\tau=\mathrm{T}=$ Tetapan waktu proses

\section{HASIL PENGUJIAN DAN ANALISA}

Dalam sub-bab pengujian dan analisa dibagi menjadi beberapa bagian: bagian yang pertama yaitu pengujian parsial dan bagian integral.

\subsection{Pengujian Parsial.}

Pada pengujian parsial ini dimasukkan data pengujian sensor LM35. Pengujian disini bertujuan untuk membandingkan pembacaan suhu oleh LM35 dan thermometer raksa. Berikut hasil pengujiannya.

Tabel 1. Hasil Pengujian sensor LM35

\begin{tabular}{|c|c|c|}
\hline Tegangan $(\mathrm{mV})$ & $\begin{array}{l}\text { Suhu di } \\
\text { LCD }\left({ }^{\circ} \mathrm{C}\right)\end{array}$ & $\begin{array}{l}\text { Suhu } \\
\text { Thermometer }\left({ }^{\circ} \mathrm{C}\right)\end{array}$ \\
\hline 281 & 28.1 & 28 \\
\hline 295 & 29.5 & 30 \\
\hline 320 & 32 & 32 \\
\hline 336 & 33.6 & 34 \\
\hline 396 & 39.5 & 40 \\
\hline 456 & 45.6 & 46 \\
\hline 501 & 50.2 & 50 \\
\hline
\end{tabular}




\begin{tabular}{|l|l|l|}
\hline 584 & 58.2 & 58 \\
\hline 635 & 63.6 & 63 \\
\hline 653 & 65.3 & 65 \\
\hline
\end{tabular}

Pada tabel 1 dapat dilihat selisih pembacaan suhu antara sensor LM35 dan thermometer raksa. Dari tabel diatas \% error berkisar antara $0 \%$ s.d. $1.66 \%$ angka tersebut didapat dari rumus :

$$
\% \text { Error }=\frac{\text { PembacaanThermometer }- \text { Pembacaan LCD }}{\text { PembacaanThermometer }} \times 100 \%
$$

Berdasarkan data table pengujian sensor LM35 dapat dibuat grafik perbandingan prosentase error sebagai berikut.

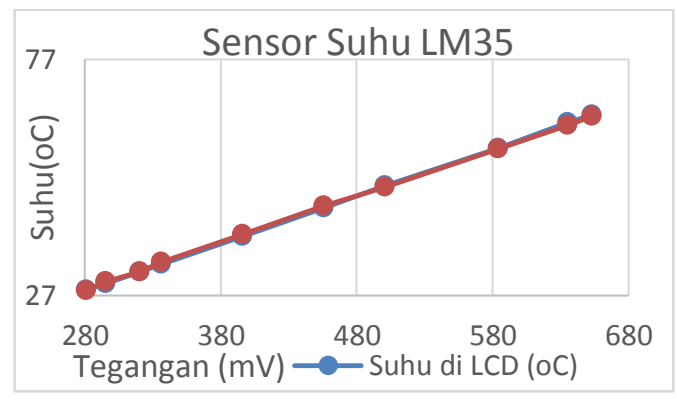

Gambar 6. Grafik Perbandingan Pembacaan suhu.

Berikut gambar hasil pengujian dari sensor LM35 yang ditampilkan pada LCD 20 x 4 .

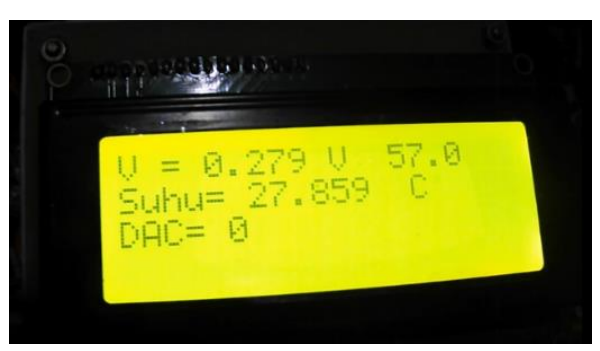

Gambar 7. Pengujian sensor LM35 yang di tampilkan di LCD.

Gambar 6 diatas terdapat data suhu $\left({ }^{\circ} \mathrm{C}\right)$. Data suhu tersebut yang dibandingkan oleh pengukuran thermometer digital.

\subsection{Pengujian Kontrol}

\subsubsection{Respon Suhu Tanpa Kontrol.}

Pada Pengujian respon suhu tanpa control, heater diberi tegangan 220v secara konstan. Pengamatan difokuskan pada berapa lama waktu yang dibutuhkan untuk mencapai set point $\left(65^{\circ} \mathrm{C}\right)$, serta berapa nilai suhu maksimal yang dapat dicapai oleh heater. Berikut adalah grafik respon suhu pengujian tanpa control.

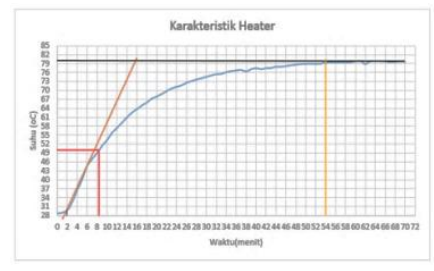

Gambar 8. Pengujian respon suhu tanpa kontrol.

\subsubsection{Perhitungan Nilai Kp dan Ki}

Berdasarkan grafik respon suhu tanpa control maka dapat dihitung besarnya nilai $\mathrm{Kp}$ dan $\mathrm{Ki}$ yang akan digunakan. Perhitungan nilai Kp dan Ki dilakukan pada 4 metode yaitu Metode Analitik, Ziegler Nichols, Chien Regulator I dan Chien Servo I.

Diketahui :

$\mathrm{L}$ (time delay) $\quad=2$ menit

$\mathrm{T}($ konstanta waktu proses $)=8.5$ menit

Ts(time settling) $\quad=54$ menit

Suhu steady $\quad=79.38 \mathrm{oC} \Rightarrow \mathrm{yss}=0.79 \mathrm{~V}$

Set point suhu $=650 \mathrm{C}=>\mathrm{xss}=0.65 \mathrm{~V}$

1. Metode Analitik

$$
\begin{array}{ll}
\circ & \mathrm{k}=\frac{y s s}{x s s}=\frac{0.79}{0.65}=1.215 \\
\circ & \text { Time Konstan }(\tau) \\
& \tau=\frac{1}{5} \mathrm{ts}=\frac{1}{5} \times 54=10.8 \text { menit } \\
\circ & \text { OLTF }=\frac{k}{\tau s+1}=\frac{1.215}{10.8 s+1} \\
\circ & \text { CLTF }
\end{array}
$$

$\mathrm{ts}^{*}=5 \tau^{*}$

ts $*=1 / \mathrm{n}^{*} \times \mathrm{ts}$

$\mathrm{ts}^{*}=1 / 5 \times 54$

$\mathrm{ts}^{*}=10.8$ menit

$$
\begin{aligned}
& \text { sehingga } \tau *=\frac{10.8}{5}=2.16 \text { menit } \\
& \text { maka CLTF }=\frac{1}{\tau * s+1}=\frac{1}{2.16 s+1} \\
& \mathrm{kp}=\frac{\tau}{k \tau *}=\frac{10.8}{1.215 \times 2.16}=4.115 \\
& \mathrm{ki}=\frac{k p}{\tau}=\frac{4.115}{10.8}=0.381
\end{aligned}
$$

2. Metode Ziegler Nichols

$$
\begin{aligned}
& \mathrm{Kp}=\frac{0.9 \tau}{K L}=\frac{0.9 \times 10.8}{1.215 \times 2}=\frac{9.72}{2.43}=4 \\
& \tau \mathrm{i}=\frac{10}{3} \mathrm{~L}=3.333 \times 2=6.666
\end{aligned}
$$

Quarter delay ratio $=>\frac{L}{T} \leq 1 \Rightarrow \frac{2}{8.5} \leq 1 \Rightarrow$ $0.235 \leq 1$

3. Metode Chien Regulator I

$$
\mathrm{Kp}=\frac{0.6 T}{K L}=\frac{0.6 \times 8.5}{1.215 \times 2.16}=\frac{5.1}{2.43}=2.098
$$


Spesifikasi $\%$ overshoot $=>0.11<\frac{L}{T}<1 \Rightarrow 0.11$

$<\frac{2}{8.5}<1 \Rightarrow 0.11<0.235<1$

4. Metode Chien Servo I

$\mathrm{Kp}=\frac{0.35 T}{K L}=\frac{0.35 \times 8.5}{1.215 \times 2}=\frac{2.975}{2.43}=1.224$

$\tau \mathrm{i}=1.17 \mathrm{~T}=1.17 \times 8.5=9.945$

\subsubsection{Pengujian Respon Suhu Dengan Kontrol PI.}

Pada pengujian ini akan diterapkan control PI guna mempertahankan suhu pada ruang pengering sesuai dengan set point yang telah ditentukan dengan nilai $\mathrm{Kp}$ dan $\mathrm{Ki}$ sesuai dengan perhitungan yang telah dilakukan.

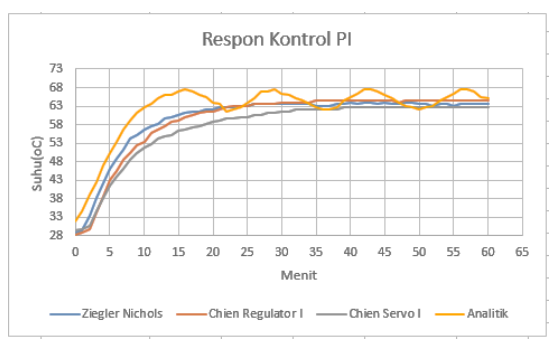

Gambar 9. Pengujian respon suhu dengan kontrol PI.

Untuk respon suhu pada metode Chien Regulator I dengan perubahan(tuning) nilai $\mathrm{Kp}$ dan $\mathrm{Ki}$ adalah seperti gambar dibawah

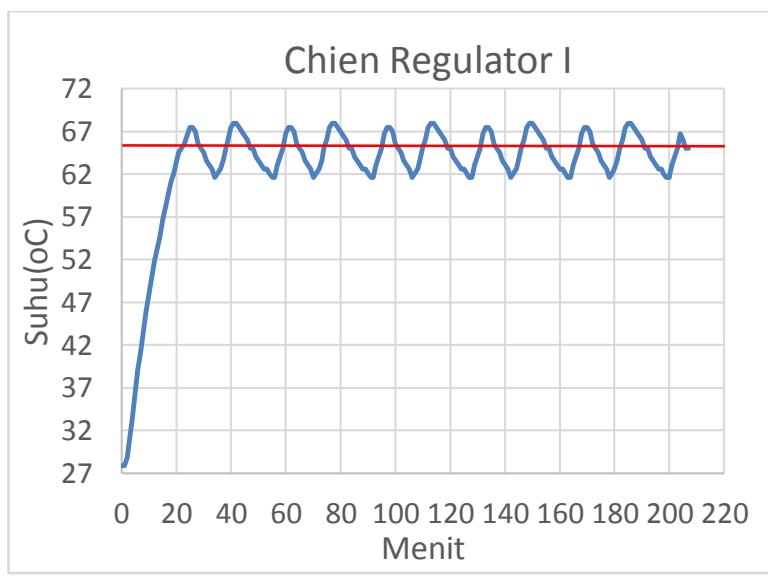

Gambar 10. Respon suhu menggunakan metode Chien Regulator I

Respon suhu diatas didapatkan dengan nilai $\mathrm{Kp}=5$ dan $\mathrm{Ki}=0.625$. berdasarkan respon suhu tersebut dapat diketahui bahwa nilai rise time yaitu 20 menit. Nilai rise time ini dapat dikatakan masih lambat. Dilihat dari segi kestabilan suhu, metode Chien Regulator yang digunakan pada sistem ini belum cukup stabil. Hal tersebut terlihat jelas dengan besarnya nilai ripple pada grafik respon.

Untuk respon suhu pada metode Chien Servo I dengan perubahan(tuning) nilai Kp dan Ki adalah seperti gambar dibawah.

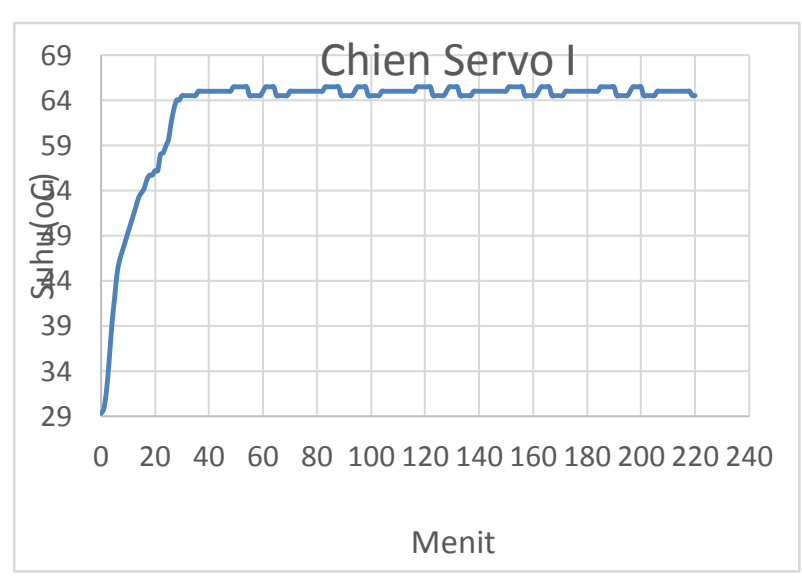

Gambar 11. Respon suhu menggunakan metode Chien Servo I

Proses pengeringan pelepah pisang menggunakan metode Chien Servo I lebih bagus dibandingkan metode Chien Regulator I, dilihat dari respon suhu yang lebih stabil dan rise time yang lebih cepat. Proses pengeringan menggunakan metode Chien Servo I dilakukan dengan nilai $\mathrm{Kp}=4.126$ dan nilai $\mathrm{Ki}=0.414$.

\section{KESIMPULAN}

Setelah dilakukan berbagai tahapan proses dalam proyek akhir ini guna mencapai tujuan yang dituliskan pada perumusan masalah dengan melakukan perencanaan, pembuatan, pengujian alat dan pembahasan antara teori dan praktek, maka dapat disimpulkan bahwa :

1. Rangkaian Ac to Ac Voltage Controller efektif digunakan pada tegangan $200-220 \mathrm{~V}$ AC atau pada peyulutan $10^{\circ}-40^{\circ}$, karena memiliki nilai rata- rata prosentase error yang sangat kecil yaitu sebesar $2,1 \%$. Untuk nilai rata- rata prosentase error diatas penyulutan $40^{\circ}$ yaitu sebesar $23,71 \%$.

2. Nilai $\mathrm{Kp}$ dan $\mathrm{Ki}$ yang diperoleh secara teori menggunakan metode analitik tidak sesuai dengan repon suhu yang diharapkan, sehingga digunakan metode try and error.

3. Proses pengeringan pelepah pisang metode control PI dengan mekanisme pengering yang telah didesain membutuhkan waktu lebih cepat jika dibandingkan dengan pengeringan secara tradisional menggunakan bantuan sinar matahari.

4. Alat pemanas pada pengering pelepah pisang dapat bekerja dengan baik. Ini dapat dibuktikan dengan respon suhu yang konstan mendekati setpoint $65^{\circ} \mathrm{C}$. 


\section{REFERENSI}

[1] Henny Farida, "Alat Pengering Bahan Baku Jamu Tradisional", Tugas Akhir Teknik Elektro Industri, PENS-ITS 2014.

[2] Nur Azizah, "Alat Pengering Keripik Gadung", Tugas Akhir Teknik Elektro Industri, PENS 2015.

[3] Sofyan Muhammad Ilman, "Rancang Bangun Pengaturan Suhu Air Dispenser Dengan Kontrol PI", Proyek Akhir Teknik Elektro Industri, PENS 2016.

[4] widodo budiharjo,2008,"Panduan Praktikum Mikrokontroller AVR ATMEGA16". Jakarta : Elex Median Komputindo.

[5] Nina Marlina, "Konversi Data Hasil Analisis Proksimat Kedalam Bahan Segar ”, Balai Penelitian Ternak, Bogor 1999.

[6] Hart, Daniel W, 2010, "Power Electronics". Indiana:Mc Graw Hill.

[7]https://www.google.com/search?q=tugas+akhir+pemana s\&ie $=$ utf $-8 \& o e=u t f-8 \& a q=t \& r l s=$ org. mozilla :enUS:official\&client=firefox-a\&channel= fflb \#channel $=f f l b \& q=$ tugas + akhir + pemanas + buah .

[8]https://www.google.com/search?q=fungsi+adaptor\&ie $=$ utf $-8 \& o e=$ utf $-8 \& a q=t \& r l s=$ org. mozilla :en US:official\&client=firefox-a.

[9]http://technologination.blogspot.co.id/2012/10/tutorialsensor-suhu-dan-kelembaban.html

[10]http://elektronika-dasar.web.id/komponen/lcd-liquidcristal-display-dot-matrix-2x16-m1632/.

[11]ttps://www.google.com/search?q=sistem+heater+pad a + microwave $\&$ ie $=$ utf $-8 \& o e=u t f$

$\& a q=t \& r l s=o r g$. mozilla:enUS:official\&client=firefox $-\mathrm{a}$.

[12]http://www.artikel.abajadun.com/2012/08/kontrolerproporsional-integral- pi.html. 